\title{
Cucumber Mosaic Virus 2b Protein Subcellular Targets and Interactions: Their Significance to RNA Silencing Suppressor Activity
}

\author{
Inmaculada González, ${ }^{1}$ Llucia Martínez, ${ }^{1}$ Daria V. Rakitina, ${ }^{2}$ Mathew G. Lewsey, ${ }^{3}$ Félix A. Atencio, ${ }^{1}$ \\ César Llave, ${ }^{1}$ Natalia O. Kalinina, ${ }^{2}$ John P. Carr, ${ }^{3}$ Peter Palukaitis, ${ }^{4}$ and Tomás Canto ${ }^{1}$ \\ ${ }^{1}$ Centro de Investigaciones Biológicas, CIB, CSIC. Ramiro de Maeztu 9, 28040 Madrid, Spain; ${ }^{2}$ A. N. Belozersky Institute \\ of Physisco-Chemical Biology, Moscow State University. Leninskie Gory 119991, Russia; ${ }^{3}$ Department of Plant Sciences, \\ University of Cambridge, Cambridge, CB2 3EA, United Kingdom; ${ }^{4}$ Department of Plant Pathology, Scottish Crop Research \\ Institute, Dundee DD2 5DA, United Kingdom
}

Submitted 15 October 2009. Accepted 5 November 2009.

\begin{abstract}
The RNA silencing suppressor activity of the $2 \mathrm{~b}$ protein of Cucumber mosaic virus (CMV) has been variously attributed to its nuclear targeting, its interaction with and inhibition of Argonaute 1 (AGO1), or its ability to bind small RNAs in vitro. In addition, the $2 b$ ortholog of Tomato aspermy virus forms aggregates and binds RNAs in vitro. We have further studied the relationships between CMV 2b protein silencing suppressor activity and its subcellular distribution, protein-protein interactions in vivo, and interactions with small interfering RNAs in vitro. To do this, we tagged the protein with fluorescent markers and showed that it retained suppressor activity. We showed that the $2 \mathrm{~b}$ protein is present in the nucleolus and that it self-interacts and interacts with AGO1 and AGO4 in vivo. Using a battery of mutants, we showed that the putative nuclear localization signals and phosphorylation motif of the $2 \mathrm{~b}$ protein are not required for self-interaction or for interaction with AGO proteins. The occurrence of neither of these interactions or of nucleolar targeting was sufficient to provide local silencing-suppression activity. In contrast, the ability of the $2 \mathrm{~b}$ protein to bind small RNAs appears to be indispensable for silencing suppressor function.
\end{abstract}

The $2 \mathrm{~b}$ protein of Cucumber mosaic virus (CMV) is a small protein that was initially identified as a pathogenicity determinant by Ding and associates $(1994,1996)$. This role is associated with its activity as a suppressor of RNA silencing (Brigneti et al.1998; Lucy et al. 2000). Subcellular fractionation studies in tobacco showed that the $2 \mathrm{~b}$ protein ( 110 amino acids) of the severe, symptom-inducing strain Fny-CMV associates mainly with the nuclear fraction and that the bulk of the protein sediments as nonsoluble aggregates (Lewsey et al. 2009; Mayers et al. 2000). This result agreed with observations from transiently expressed $2 \mathrm{~b}$ protein that was either $\mathrm{C}$-terminally tagged with green fluorescent protein (GFP) or N-terminally tagged with $\beta$-glucuronidase (GUS). The Fny-CMV $2 b$ protein tagged at its $\mathrm{N}$-terminus with GUS displayed nuclear localization in onion

Current address for P. Palukaitis: Division of Environmental and Life Sciences, Seoul Women's University, Seoul 139-74, Korea.

Corresponding author: Tomas Canto; E-mail: tomas.canto@cib.csic.es

* The $\boldsymbol{e}$-Xtra logo stands for "electronic extra" and indicates that three supplemental figures are published online. epidermal cells (Wang et al. 2004). Likewise, 2b protein from the milder symptom-inducing Q strain of CMV or from strain CM95, both tagged with GFP at their C-termini, also accumulated inside the nucleus in Nicotiana glutinosa and onion epidermal cells, respectively (Goto et al. 2007; Lucy et al. 2000). In both cases, its presence in specific subnuclear structures was not reported. The biological activities as suppressors of gene silencing of the tagged constructs were also not tested in those reports.

Nuclear targeting of $2 \mathrm{~b}$ is thought to be required for its function as a silencing suppressor, as the loss of nuclear localization sequences (NLS) in some mutants also abolished the silencing suppressor activity (Lucy et al. 2000; Wang et al. 2004). The N-terminus of the Fny-CMV $2 b$ protein is rich in basic hydrophilic lysine $(\mathrm{K})$ and arginine $(\mathrm{R})$ residues, arranged in what could constitute two putative NLS, NLS1, amino acids 22 to $27 \mathrm{KKQRRR}$, and NLS2, amino acids 33 to 36 RRER ( $Q$ and $E$ being the nonbasic residues glutamine and glutamic acid, respectively), which could mediate protein transit from the cytoplasm into the nucleus. More recently, the manner in which the protein performs its suppressor role has been related to its interaction and subsequent inhibition of Argonaute 1 (AGO1), a component of the RNA-induced slicing complex (RISC), which is part of the plant antiviral silencing machinery (Zhang et al. 2006). Presumably, the antiviral slicing activity of RISC would take place in the cytoplasm. However, the $2 \mathrm{~b}$ protein also can bind directly to small RNAs in vitro (Goto et al. 2007) and this could also be how it performs its suppression-of-silencing role. These independent studies suggest the possibility that cucumoviral $2 \mathrm{~b}$ proteins might be eliciting their suppressor response through a dual strategy of direct binding to double-stranded (ds)RNAs, coupled with inhibiting the slicing activity of antiviral RISC complexes through binding of AGO proteins. As these two processes presumably would take place in the cytoplasm, they also raise the question of why nuclear targeting seems to be needed for the $2 \mathrm{~b}$ protein's biological function as a silencing suppressor.

It is not uncommon for nonstructural viral proteins to aggregate to become functional in vivo, and this is the case for some suppressors of silencing, such as the tombusviral P19 protein, which dimerizes (Ye et al. 2003). The biologically active form of the CMV $2 \mathrm{~b}$ protein is not known. However, in vitro crystallographic data for Tomato aspermy virus (TAV) $2 \mathrm{~b}$ suggest that homodimers or higher-order oligomers could constitute one or more functionally active forms of cucumoviral $2 \mathrm{~b}$ pro- 
teins. The crystal structure of the TAV $2 \mathrm{~b}$ protein ortholog shows that it dimerizes in the absence of nucleic acids, while in the presence of dsRNAs, to which it binds through hydrogen bonds, it forms tetramers by means of a conserved leucine-zipper domain at its N-terminus (Chen et al. 2008; Rashid et al. 2008). In the case of Fny-CMV 2b protein this leucine-rich motif is, however, not completely conserved. CMV $2 \mathrm{~b}$ protein may also require self-interaction to become a functional suppressor of silencing.

Whatever the means used to achieve silencing, the suppressor activity of CMV $2 b$ protein reduces the levels of three classes of antiviral small interfering (si)RNAs in Arabidopsis $d c l$ mutant plants (of 21, 22, and 24 nt in length), generated upon viral infection by Dicer-like (DCL) ribonucleases, DCL4, DCL2, and DCL3, respectively (Díaz-Pendón et al. 2007). Plant AGO1 binds to the DCL4-derived 21-nt small RNAs, among them antiviral siRNAs, whereas AGO4 binds to DCL3-derived 24-nt siRNAs (Mi et al. 2008). AGO1 localization in the cell appears to be both cytoplasmic and nuclear (Vaucheret 2008), whereas AGO4 localizes mainly to nucleolus-associated bodies (Li et al. 2006). In addition to this, studies using constitutive transgenic expression of the $2 b$ protein showed that the suppressor can also interfere with the endogenous microRNA pathway, although in a manner that is dependent on the strain of CMV and on the severity of symptoms it induces (Chapman et al. 2004; Lewsey et al. 2007; Zhang et al. 2006).

In this work, we have further investigated the relevance to CMV 2b suppressor activity of its subcellular distribution, protein-protein interactions in vivo, and interactions with small RNAs in vitro. We have tagged native and mutant forms of the Fny CMV 2b protein with different fluorescent markers to determine its subcellular localization in vivo and the occurrence of molecular protein-protein interactions. We also tested in vitro their binding to small RNAs. To further study their possible role in the protein function, we have, in parallel, determined the biological activities of these constructs as suppressors of RNA silencing. We have found that both $\mathrm{N}$ - or $\mathrm{C}$ - terminally tagged $2 \mathrm{~b}$ proteins retained local suppression of gene silencing activity in agroinfiltration patch assays. We have shown that the $2 \mathrm{~b}$ protein is present in the nucleolus. We have visualized both $2 b$ protein self-interaction and $2 b$ interaction with AGO1 and AGO4 in the living cell. Mutants with deletions affecting either one or both NLS or the putative phosphorylation site showed no suppressor activity in patch assays. While all four mutants retained their ability to self-interact and to interact with AGO1 and AGO4 in vivo, their subcellular localization phenotypes were differentially altered by the mutations, as was their ability to bind to synthetic siRNAs in vitro.

\section{RESULTS}

\section{2b protein tagged with fluorescent markers} retains its activity in local silencing-suppression assays.

To analyze in detail the subcellular distribution of $2 b$ in vivo, we examined $2 \mathrm{~b}$ proteins tagged with different fluorescent markers or termini, or both, while simultaneously assessing their performance as suppressors of RNA silencing. The modified $2 \mathrm{~b}$ proteins were expressed transiently in Nicotiana benthamiana leaf epidermal cells by agroinfiltration, and fluorescence was analyzed by confocal microscopy. The $2 \mathrm{~b}$ protein was tagged at its $\mathrm{C}$-terminus with monomeric red fluorescent protein (2b-mRFP) or at its N-terminus with GFP (GFP-2b) (Fig. 1). In the case of 2b-mRFP, fluorescence seemingly accumulated in nuclei of epidermal cells (Fig. 1A and N, arrows), which were shown to be nuclei by 4'-6-diamino-phenylindol (DAPI) staining (Fig.1A and B). Fluorescence was present in what appeared to be nucleoli (Fig. 1C, arrows). In addition, some weaker fluorescence was present in the cytoplasm (Fig. 1A). Tagging the $2 \mathrm{~b}$ protein at its $\mathrm{N}$-terminus with GFP (GFP2b) also resulted in a pattern of fluorescence that was both nuclear and cytoplasmic (Fig. 1D). Inside nuclei, fluorescence accumulated in structures that seemed to correspond to nucleoli (Fig. 1E, arrow). This pattern of fluorescence is different from that derived from free GFP, which targets both cytoplasm and nucleus but is excluded from the nucleolus (Fig. 1F, arrow). Indeed, when GFP-2b was coexpressed with fibrillarin fused to mRFP (Fib-mRFP), a marker of nucleolus and Cajal bodies (Kim et al. 2007), both colocalized (Fig. 1G). Therefore, 2b$\mathrm{mRFP}$ and GFP-2b are present in nucleoli and other nucleolusassociated bodies.

To analyze the silencing-suppression activity of $2 b$ proteins tagged with fluorescent markers, we tested their ability to suppress the silencing of a transiently expressed GFP reporter
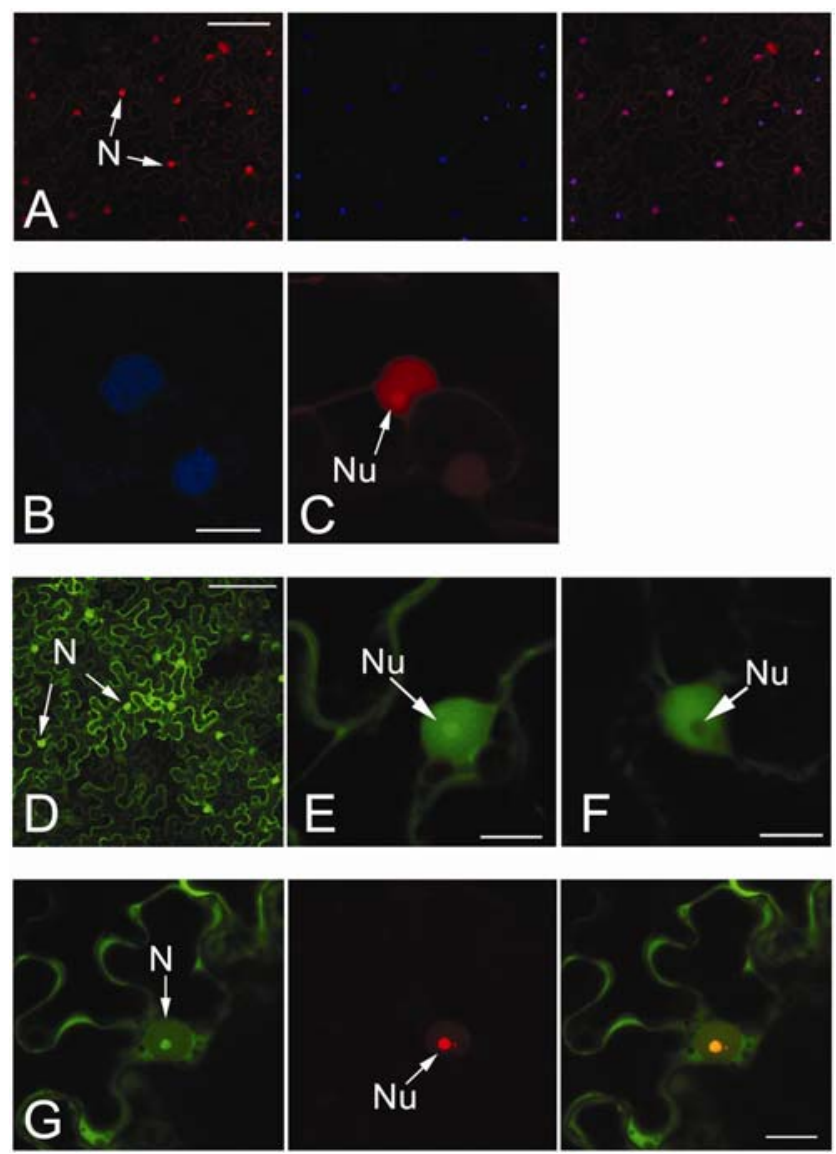

Fig. 1. Subcellular distribution of tagged $2 b$ proteins expressed transiently by agroinfiltration. A, Fluorescence derived from Cucumber mosaic virus (CMV) $2 \mathrm{~b}$ protein tagged at its $\mathrm{C}$-terminus with monomeric red fluorescent protein (mRFP) in a field of epidermal cells seemingly localized to nuclei ( $\mathrm{N}$, arrows in left panel). The nuclear nature of the spots was confirmed by 4'-6-diamino-phenylindol (DAPI)-staining (middle panel). The right panel shows an overlay of the previous two panels. B, A close-up view of individual nuclei with DAPI and $\mathbf{C}, 2 \mathrm{~b}$-mRFP fluorescence showed the presence of the latter within the nucleolus $(\mathrm{Nu}$, arrow). $\mathbf{D}$, Fluorescence derived from CMV $2 b$ protein tagged at its $\mathrm{N}$-terminus with green fluorescent protein (GFP). Arrows point to some nuclei. E, Close-up view of fluorescence derived from GFP-2b in nuclei of epidermal cells. It is present in structures resembling nucleoli (arrows). F, Close-up view of fluorescence derived from free GFP in nuclei. It is absent from the nucleolus ( $\mathrm{Nu}$, dark spot inside the nucleus). G, Subcellular distribution of GFP$2 \mathrm{~b}$ coinfiltrated with fibrillarin tagged with mRFP (Fib-mRFP). Within the nucleus, GFP-2b fluorescence (left panel) colocalized with that of FibmRFP (middle panel), a marker of the nucleolus $(\mathrm{Nu})$, as shown in the merged image (right panel). Bars in upper and lower right corner of images represent 100 and $10 \mu \mathrm{m}$, respectively. 
gene from a binary T-DNA vector agroinfiltrated into $N$. benthamiana leaves (Canto et al. 2002; Johansen and Carrington 2001). When this $G F P$ vector was coinfiltrated with an empty vector, transient accumulation of GFP produced fluorescence under the UV lamp (Fig. 2A, right side of each leaf). When the $G F P$ vector was coinfiltrated with a vector expressing native $2 \mathrm{~b}$, the level of GFP-derived fluorescence increased markedly, as a result of the easing of the silencing of the ectopic GFP

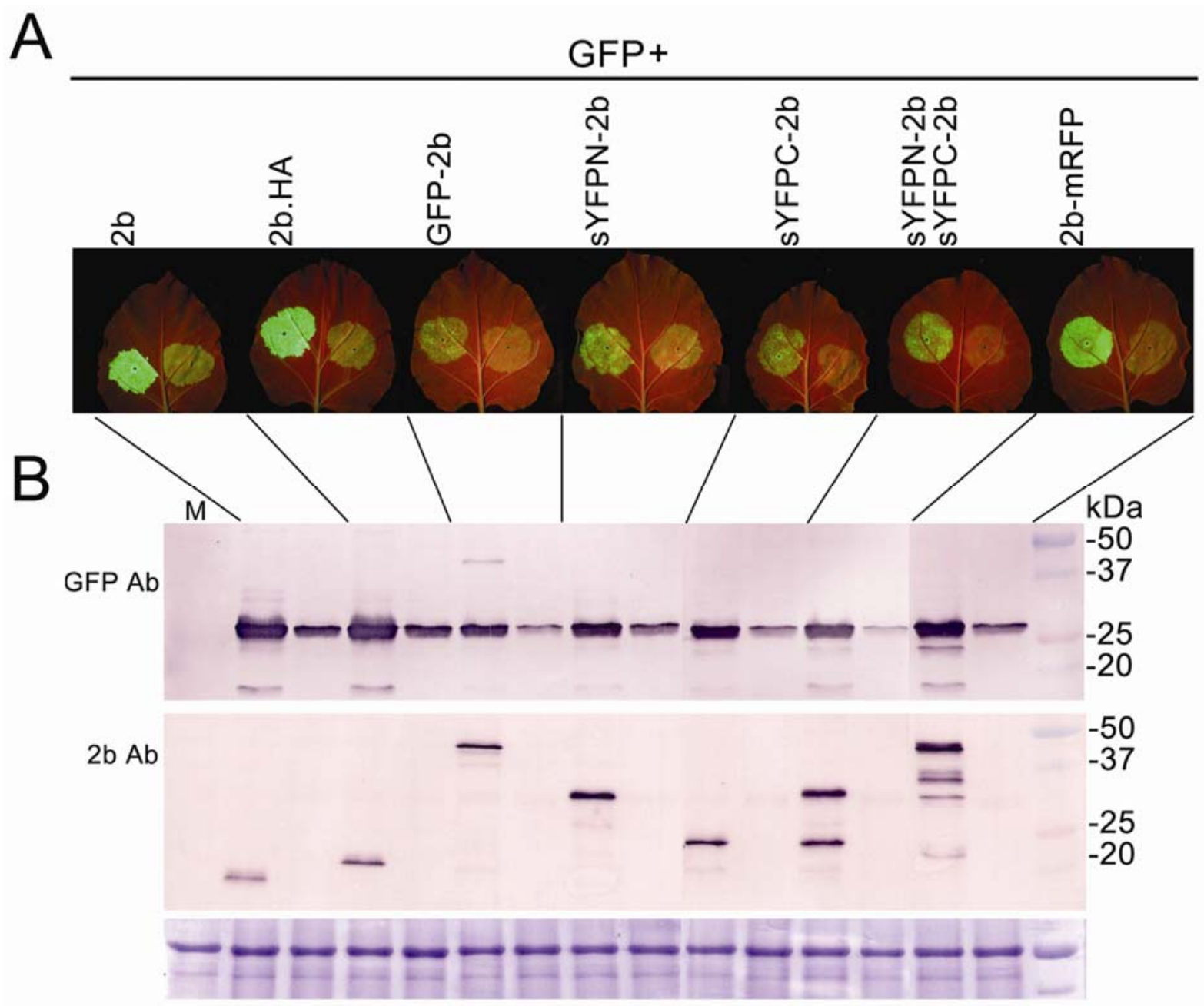

C
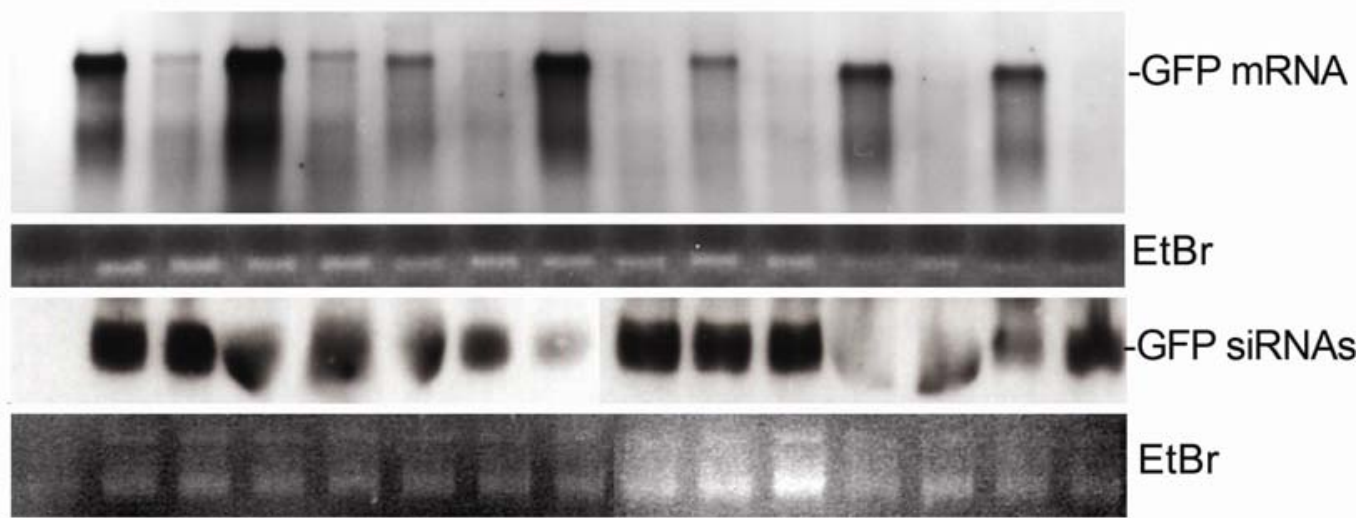

$\mathrm{EtBr}$

Fig. 2. Cucumber mosaic virus (CMV) $2 \mathrm{~b}$ proteins tagged at their N- or C-termini retain suppressor-of-RNA-silencing activity in patch assays. Green fluorescent protein (GFP) was expressed transiently in Nicotiana benthamiana leaves from a binary vector coinfiltrated together with an empty 35SP-Nost vector (infiltrated area in right side of the leaves) or with binary vectors expressing wild-type or tagged $2 \mathrm{~b}$ proteins: $2 \mathrm{~b}$ tagged at its $\mathrm{C}$-terminus with either hemagglutinin (HA) peptide (2b-HA), $2 b$ tagged at its N-terminus with GFP (GFP-2b), split yellow fluorescent protein halves (sYFPN-2b or sYFPC-2b), either alone or combined, or monomeric red fluorescent protein (2b-mRFP) (left to right leaves, respectively). A, Coinfiltration of the reporter GFP gene with either wild type or tagged forms of $2 \mathrm{~b}$ protein induced enhancement of fluorescence under the UV lamp in all cases (left vs. right side of corresponding leaves). B, The enhancement of fluorescence observed in the presence of the suppressors correlated with detection of higher levels of GFP by Western blot analysis using a GFP antibody (upper panel). The presence of wild-type and tagged $2 \mathrm{~b}$ proteins was confirmed using $2 \mathrm{~b}$ antibody (middle panel). $\mathrm{M}$ line represents buffer-infiltrated tissue. The lower panel is a control of loading. C, Analysis of the transient GFP mRNA accumulation in infiltrated tissues (upper panel) and the presence of GFP small interfering (si)RNAs in the same samples (middle panel). The enhancement of fluorescence observed in the presence of the suppressors correlated with detection of higher levels of GFP mRNAs. The corresponding panels below show ethidium bromide-stained gels as loading controls. 
mRNA (Fig. 2A, left side of first leaf from the left). When the wild-type $2 b$ was replaced in the assay by $2 b$ with a $C$-terminal hemagglutinin (HA) tag (2b-HA), GFP-2b, 2b fused to split yellow fluorescent protein halves (sYFPN-2b, sYFPC-2b, or both together), or $2 b-m R F P$, an increase in fluorescence was observed under the UV lamp in all six cases (Fig. 2A, left vs. right side in infiltrated patches of the corresponding leaves). This was confirmed by the analysis of transient GFP accumulation (Fig. 2B) and of the GFP mRNA levels (Fig. 2C, upper panel) in infiltrated tissues.

The levels of GFP reached in the absence of a suppressor vary between leaves (Fig. 2A, right side of different leaves). For this reason, fluorescence cannot be compared between individual leaves, and each leaf should have its own internal control (infiltrated patch in right side). If these internal controls were not taken into account, comparison of fluorescence between the GFP-2b and native $2 b$-infiltrated patches shown in Figure 2A would suggest that the former has less suppressor activity than the latter. This is not the case; when this assay was performed within the same leaf, GFP-2b did not show diminished suppressor activity as compared with wild-type $2 b$ (Supplemental Fig. 1).

\section{Bimolecular fluorescence complementation (BiFC) shows $2 \mathrm{~b}$ protein self-interaction as well as interaction} with more than one member of the Argonaute family in vivo.

Proteins perform their biological function by means of interactions with other molecules in compartmentalized spaces. In regard to CMV 2b, in vitro crystallographic data from the TAV ortholog suggests that homodimers or higher order oligomers could constitute one or more of its functional forms in the cell (Rashid et al. 2008; Zhang et al. 2006). To visualize potential protein-protein interactions involving the $2 \mathrm{~b}$ protein in the living cell and their subcellular occurrence, we tagged CMV $2 b$ as well as AGO1 and AGO4 with sYFP halves (sYFPN and sYFPC, respectively) for BiFC. AGO1 and AGO4 were chosen because the former has been shown previously to interact with the $2 \mathrm{~b}$ protein in vitro, while transcription of the latter is negatively affected by the $2 \mathrm{~b}$ protein (Zhang et al. 2006; Ye et al. 2009, respectively). Native AGO1 localization in the cell appears to be both cytoplasmic and nuclear (Vaucheret 2008), whereas AGO4 localizes mainly to nucleolus-associated bodies (Li et al. 2006).

Our BiFC results show that the $2 \mathrm{~b}$ protein interacts strongly with itself in vivo. The distribution of fluorescence derived from the reconstitution of the YFP fluorophore after sYFPN-2b and sYFPC-2b interaction was mainly nuclear (Fig. 3A and N, arrows), but there was also some cytoplasmic fluorescence. This pattern is similar to that displayed by GFP-2b. Within the nucleus, sYFPN-2b + sYFPC-2b fluorescence was present in the nucleolus and colocalized with fibrillarin-mRFP (Fig. 3B to $\mathrm{D})$. When the binary vector expressing sYFPN-2b was coexpressed with the binary vector expressing sYFPC alone or the binary vector expressing sYFPC-2b was coexpressed transiently with the binary vector expressing sYFPN alone, no fluorescence was detected (Fig. 3E and F).

Using BiFC, we also detected fluorescence derived from the interaction between sYFP-tagged $2 \mathrm{~b}$ and AGO1 proteins, although weaker than that observed in the $2 b-2 b$ interaction. We observed fluorescence both in the cytoplasm and nucleus (Fig. $4 \mathrm{~A}$ and $\mathrm{B}$ ). However, we also found fluorescence derived from the interaction between $2 \mathrm{~b}$ and AGO4 proteins. Fluorescence was more pronounced in the nucleus (Fig. 4C and D) but seemed absent from the nucleolus ( $4 \mathrm{C}$ and $\mathrm{D}$, insets, indicated by arrows). BiFC between $2 b$ and AGO1 as well as between $2 \mathrm{~b}$ and $\mathrm{AGO} 4$ occurred in the two combinations of tagged proteins, with similar patterns (Fig. 4, left vs. right panels). West- ern blot analysis of the accumulation of sYFP-tagged proteins in infiltrated tissue revealed that $\mathrm{AGO}$ proteins accumulated to levels that were only a fraction of those reached by the $2 \mathrm{~b}$ protein (Fig. 4E).

Four different mutations in the $2 \mathrm{~b}$ protein abolish local suppression of silencing in patch assays but affect its subcellular distribution differently.

To study how the biological function of the CMV $2 \mathrm{~b}$ protein as a silencing suppressor relates to its ability to target the nucleoplasm and nucleolus, we studied the biological activity of different $2 b$ protein mutants in agroinfiltrated patch silencingsuppression assays and the protein's subcellular localization. To facilitate this, three $2 \mathrm{~b}$ deletion mutants affecting the putative nuclear localization signals NLS1 (amino acids 22 to 27), NLS2 (amino acids 33 to 36), both NLS1 and NLS2 were expressed from binary vectors in plants, with C-terminal HA peptide tags. In addition, a deletion mutant affecting the puta-
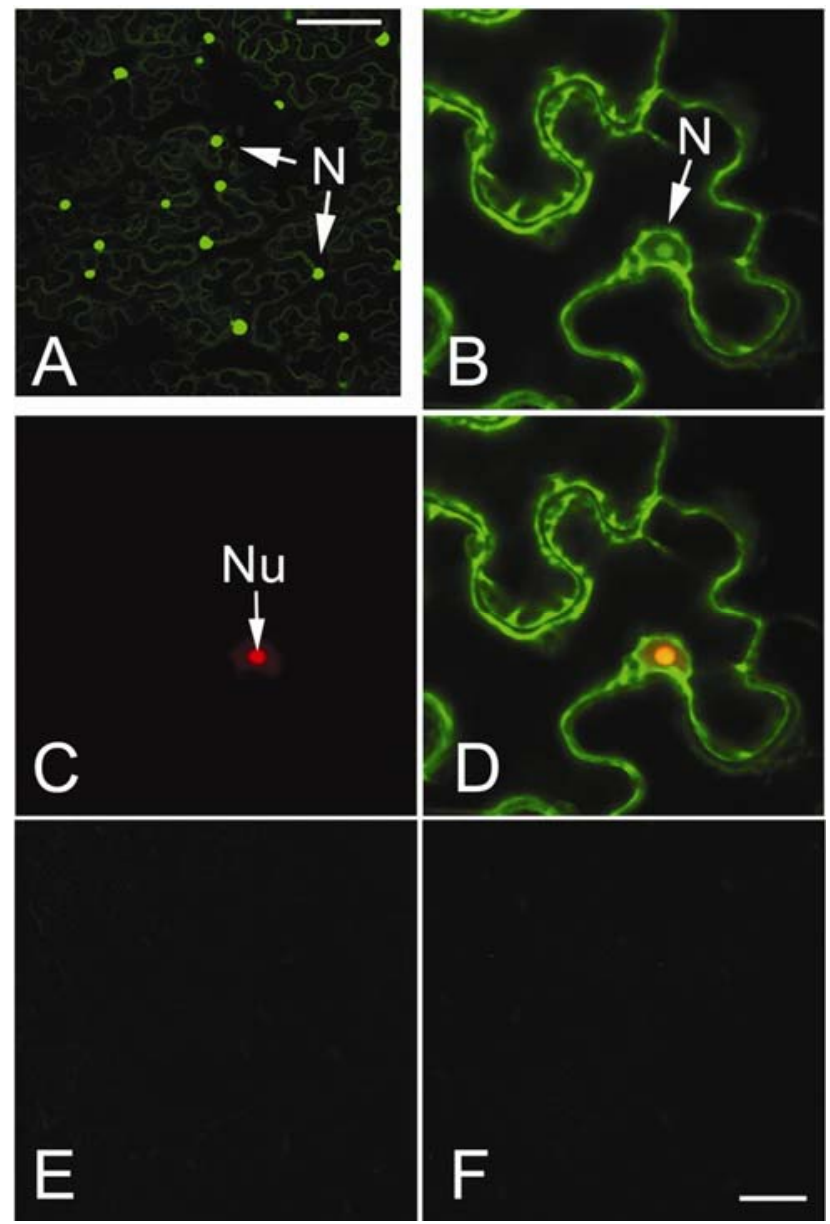

Fig. 3. The $2 b$ protein self-interacts in vivo. The $2 b$ protein was tagged at its $\mathrm{N}$ terminus with yellow fluorescent protein (YFP) halves (sYFPN-2b and sYFPC-2b) to study protein-protein interactions in vivo by bimolecular fluorescence complementation. A, When both sYFPN-2b and sYFPC$2 \mathrm{~b}$ were coexpressed transiently in Nicotiana benthamiana leaves, fluorescence was detected with a pattern similar to that displayed by $2 \mathrm{~b}-\mathrm{mRFP}$ (monomeric red fluorescent protein) or green fluorescent protein (GFP)$2 \mathrm{~b}$, mainly nuclear but also cytoplasmic. B, Within nuclei, sYFPN-2b + sYFPC-2b fluorescence and $\mathbf{C}$, that from fibrillarin tagged with mRFP, a marker of the nucleolus $(\mathrm{Nu})$ colocalized in $\mathbf{D}$, the merged image. As controls, under the same settings the binary vector expressing sYFPN-2b was coexpressed with $\mathbf{E}$, the binary vector expressing sYFPC alone, and the binary vector expressing sYFPC-2b was coexpressed transiently with $\mathbf{F}$, the binary vector expressing sYFPN alone. The bar in A represents $100 \mu \mathrm{m}$, and the bar in $\mathrm{F}$ is representative of $10 \mu \mathrm{m}$ in panels $\mathrm{B}$ through $\mathrm{F}$ 
tive phosphorylation site KSPSE (amino acids 39 to 43) as well as two mutants with point mutations of Ser to Ala in the same putative phosphorylation site at amino acids 40 and 42 , respectively (Fig. 5A), were also expressed from binary vectors in plants, with $\mathrm{C}$-terminal HA peptide tags. The effect of these six $2 b$ mutations on viral infection had previously been
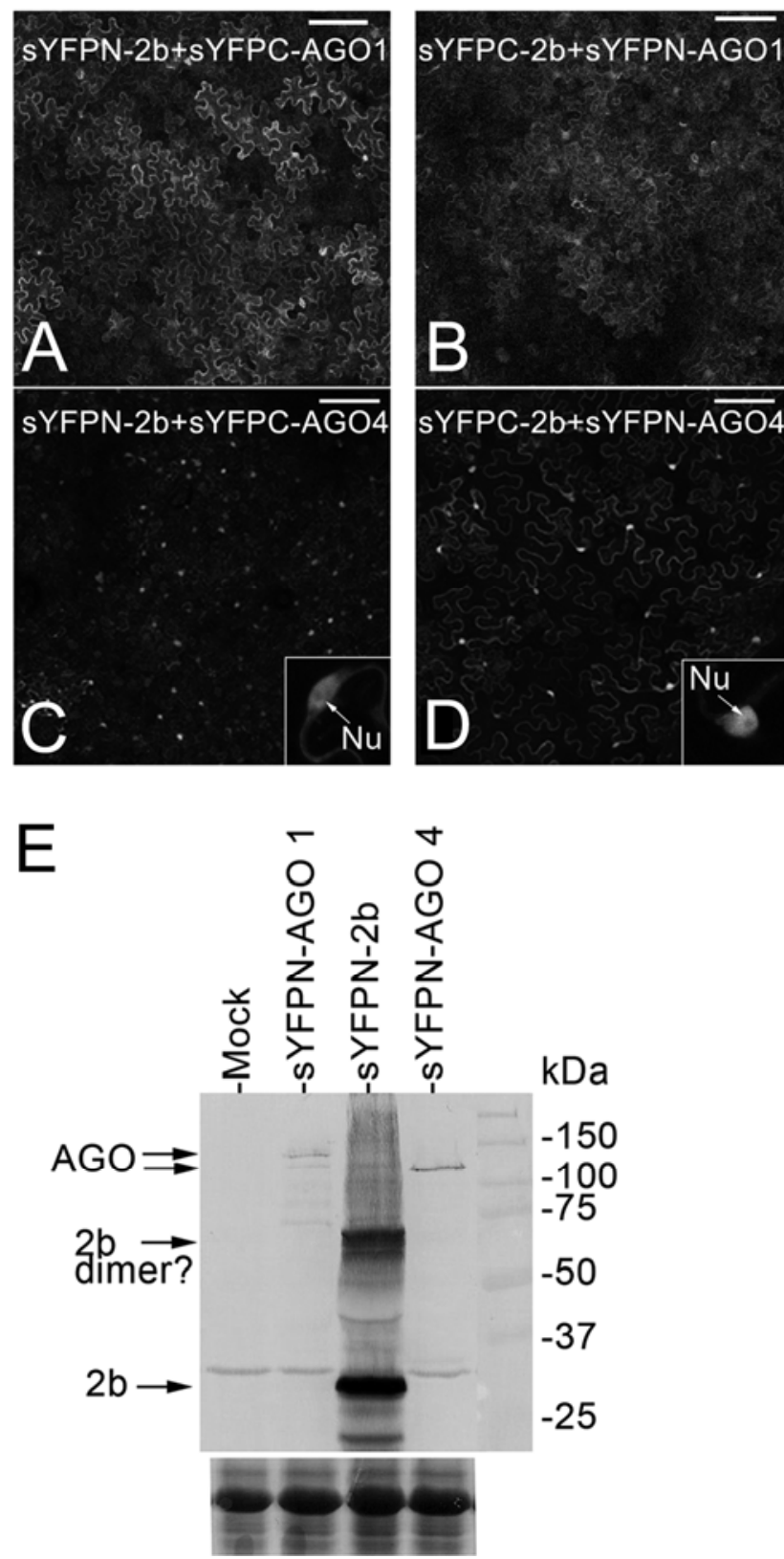

Fig. 4. Bimolecular fluorescence complementation (BiFC) between $2 b$ and Argonaute proteins 1 and 4 , tagged at their $\mathrm{N}$ termini with split yellow fluorescent protein halves (sYFPN-2b, sYFPN-AGO1, sYFPN-AGO4, sYFPC-2b, sYFPC-AGO1, and sYFPC-AGO4) and their subcellular occurrence. $\mathbf{A}$ and $\mathbf{B}, \mathrm{BiFC}$-derived fluorescence in fields of epidermal cells, in tissues expressing sYFPN-2b + sYFPC-AGO1, or sYFPC- $2 b+s Y F P N-$ AGO1, respectively. Weak fluorescence was distributed throughout the cytoplasm and nucleus. $\mathbf{C}$ and $\mathbf{D}, \mathrm{BiFC}$-derived fluorescence in fields of epidermal cells, in tissues expressing sYFPN-2b + sYFPC-AGO4, or sYFPC-2b + sYFPN-AGO4, respectively. Weak fluorescence was pronouncedly nuclear but seemed absent from the nucleolus ( $\mathrm{Nu}$, insets). Bars in the upper right corner of images represent $100 \mu \mathrm{m}$. E, Western blot detection of sYFPN-AGO1, sYFPN-2b, and sYFPN-AGO4 accumulation in infiltrated tissues (upper panel). The accumulation of AGO constructs (two upper arrows) was several fold lower than that of the $2 \mathrm{~b}$ construct (lower arrow). Mock line represents buffer-infiltrated tissue. The lower panel is a control of loading. characterized in Nicotiana spp. and Arabidopsis thaliana by Lewsey and associates (2009). Four of the six constructs, $2 \mathrm{~b} \Delta \mathrm{NLS} 1,2 \mathrm{~b} \Delta \mathrm{NLS} 2,2 \mathrm{~b} \Delta \mathrm{NLS} 1+2$, and $2 \mathrm{~b} \triangle \mathrm{KSPSE}$, failed to suppress the silencing of a $G F P$ reporter gene in patch assays, while the two Ala-substitution mutants retained local suppres-
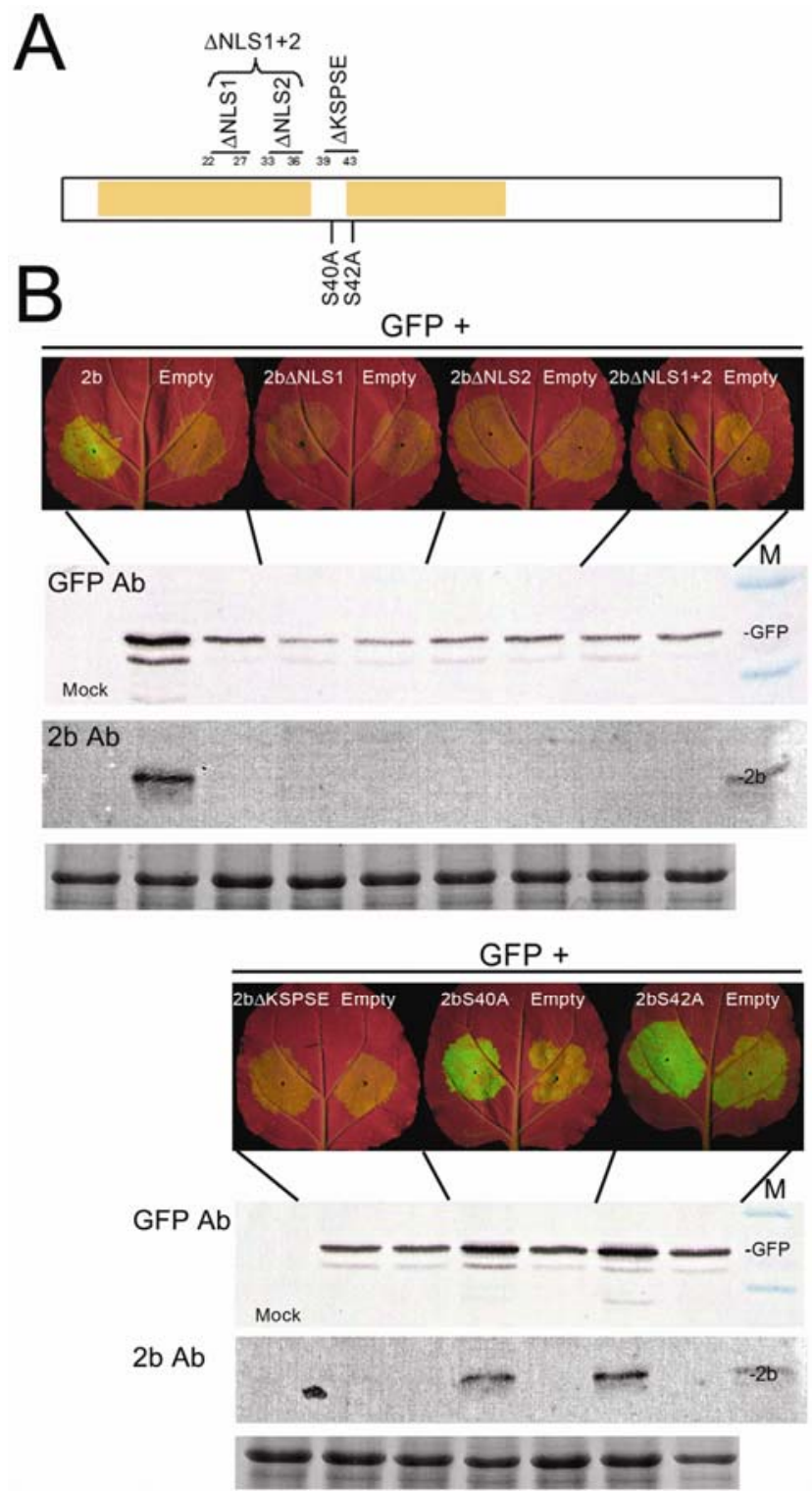

Fig. 5. Local silencing-suppressor activity of six $2 \mathrm{~b}$ protein mutants in infiltrated patch assays. A, Schematic representation of the six different mutations on the $2 \mathrm{~b}$ protein. Three mutants had deletions in either or both of the putative nuclear localization signals of the protein ( $\triangle \mathrm{NLS1}, \triangle \mathrm{NLS} 2$ or $\Delta \mathrm{NLS} 1+2)$, one mutant had a deletion in a putative protein phosphorylation site ( $\triangle$ KSPSE), and two further mutants had point Ala mutations within the same putative phosphorylation site (S40A and S42A) (Lewsey et al. 2009). The boxes represent two putative $\alpha$ helices in the Cucumber mosaic virus $2 \mathrm{~b}$ that are equivalent to those in the $2 \mathrm{~b}$ ortholog of Tomato aspermy virus (Chen et al. 2008). B, Green fluorescent protein (GFP) was expressed transiently in Nicotiana benthamiana plants from a binary vector infiltrated together with an empty 35SP-Nost vector (infiltrated area in right side of the leaves) or with binary vectors expressing $\mathrm{C}$-terminally hemagglutinin-tagged $2 b, 2 b \Delta N L S 1,2 b \Delta N L S 2,2 b \Delta N L S 1+2,2 b \Delta K S P S E, 2 b S 40 A$, or $2 b S 42 \mathrm{~A}$. Coinfiltration of the reporter GFP gene with either wild-type or the two Alapoint $2 \mathrm{~b}$ mutants induced a comparable enhancement of fluorescence in the infiltrated area of the leaf under a UV lamp (photographs of leaves), which correlated with increased accumulation of GFP in the infiltrated tissue (upper panel) and with detection of $2 \mathrm{~b}$ protein (middle panel). By contrast, the four deletion mutants failed to increase the amount of GFP and to accumulate in infiltrated areas (upper and middle panels, respectively). Mock line represents buffer-infiltrated tissue. The lower panels are controls of loading. 
sor of silencing activity comparable to that of wild-type $2 b$ (Fig. 5B, left vs. right side of leaves and upper panel Western blot). Western blot analysis showed that these four mutants failed to accumulate in infiltrated tissue (Fig. 5B, middle panel Western blot)

To test how the mutations affected the protein subcellular localization, in particular its presence in the nucleoplasm and nucleolus, the six mutants had the GFP fused at their N-termini to generate GFP-2b $\Delta$ NLS1, GFP-2b $\Delta$ NLS2, GFP-2b $\Delta N L S 1+2$, GFP-2b $\Delta$ KSPSE, GFP-2bS40A, and GFP-2bS42A. The constructs were expressed transiently in plants from agroinfiltrated binary vectors, and fluorescence from epidermal cells was monitored (Fig. 6). In a similar way to what we observed with the accumulation of HA-tagged $2 \mathrm{~b}$ mutants (Fig. 5B, middle panel), Western blot analysis revealed that the four GFPtagged $2 b$ deletion mutants GFP-2b $\Delta$ NLS1, GFP-2b $\Delta$ NLS2, GFP- $2 \mathrm{~b} \Delta \mathrm{NLS} 1+2$ or GFP-2b $\Delta$ KSPSE often accumulated poorly in infiltrated tissue, and fluorescence was barely or not detectable. By contrast, constructs GFP-2bS40A and GFP$2 \mathrm{bS} 42 \mathrm{~A}$ consistently accumulated to levels similar to those of GFP-2b (Fig. 6A, and data not shown). These two mutants also retained silencing-suppression activity in patch assays when tagged with HA (Fig. 5B). These patterns of accumulation correlate with those observed when these mutant $2 b$ proteins were expressed during viral infection (Lewsey et al. 2009). Those authors suggested that poor accumulation was caused by either low virus titers or instability of the mutant $2 \mathrm{~b}$ proteins (Lewsey et al. 2009). Alternatively, poor accumulation could be caused by a lack of RNA silencing-suppression activity. If the latter was the case, coexpression with the Tomato bushy stunt virus P19 RNA-silencing suppressor would restore the levels of the mutants to those of the wild-type protein, and this was broadly the case (Fig. 6B). However, accumulation of the GFP-2b or GFP-2bS40A, and GFP-2bS42A proteins, which all maintained suppressor competence, were not increased in the presence of P19 (Fig. 6A vs. B).

The beneficial effect of $\mathrm{P} 19$ on the accumulation of the four $2 \mathrm{~b}$ protein deletion mutants (GFP-2b $\Delta$ NLS1, GFP-2b $\Delta$ NLS2, GFP-2b $\Delta$ NLS $1+2$ or GFP-2b $\Delta$ KSPSE) allowed us to examine their subcellular distribution patterns. Fluorescence from GFP fusions to wild-type $2 b$ accumulated mainly within nuclei of epidermal cells, including nucleoli (Fig. 1D), as was that from mutants $2 \mathrm{bS} 40 \mathrm{~A}$ or $2 \mathrm{bS} 42 \mathrm{~A}$ (data not shown). By contrast, for the three NLS deletion mutants, fluorescence in fields of epidermal cells was predominantly cytoplasmic, and a closer look at cell nuclei revealed that GFP-2b $\Delta \mathrm{NLS} 1$ and GFP$2 \mathrm{~b} \Delta \mathrm{NLS} 1+2$ were absent from the nucleolus. GFP-2b $\Delta \mathrm{NLS} 1$ displayed some strong perinuclear fluorescence, GFP$2 \mathrm{~b} \Delta \mathrm{NLS} 2$ displayed a weak nucleolar presence, whereas GFP2b $\triangle$ KSPSE showed a marked targeting to nucleoli (Fig. 6C).

\section{Four different mutations in the $2 \mathrm{~b}$ protein that abolish local suppression of silencing in patch assays do not prevent $\mathbf{2 b}-\mathbf{2 b}$ or $\mathbf{2 b - A G O}$ interactions.}

To test whether the six mutations would affect the ability of the $2 \mathrm{~b}$ protein to self-interact, mutants were fused to sYFPN or sYFPC halves for BiFC studies. Western blot analysis showed that the four deletion mutants accumulated poorly in infiltrated patches (Fig. 7A), and little or no BiFC-derived fluorescence could be detected from these four deletion constructs (data not shown). However, the two Ala-substitution mutants did accumulate to levels similar to those shown by sYFPN-2b + sYFPC-2b (Fig. 7A). The presence of P19 restored the levels of the four sYFP-2b deletion mutants to those of the wild-type protein or the two Ala mutants (Fig. 7B). In every case, all four deletion mutants retained their ability to self-interact. The subcellular distribution of fluorescence was mainly cytoplasmic and perinuclear for constructs $2 \mathrm{~b} \Delta \mathrm{NLS} 1,2 \mathrm{~b} \Delta \mathrm{NLS} 2$, and $2 \mathrm{~b} \Delta \mathrm{NLS} 1+2$, respectively, while it remained cytoplasmic and nuclear for constructs S40A and S42A and strongly nucleolar for mutant $2 \mathrm{~b} \triangle \mathrm{KSPSE}$ (Fig. $7 \mathrm{C}$ and D). The distribution of
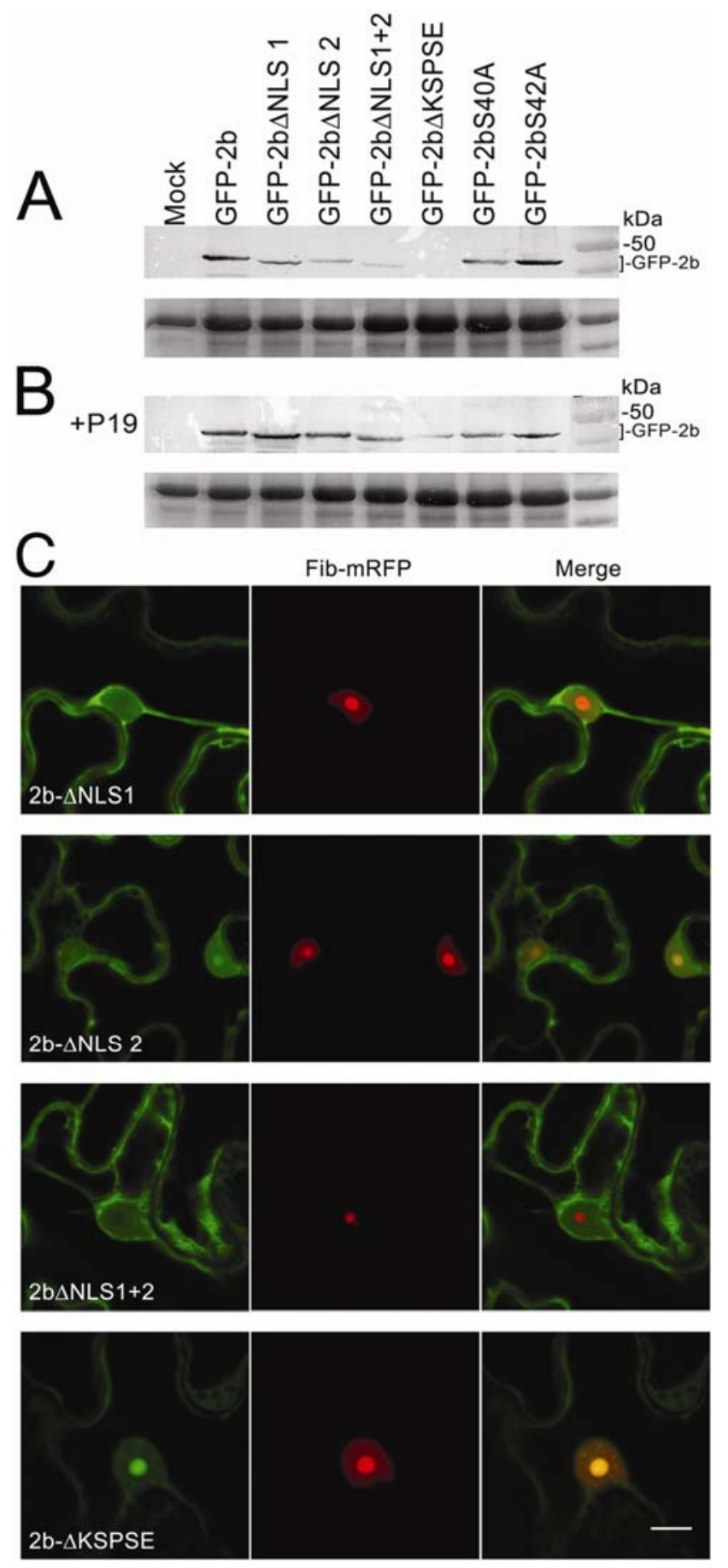

Fig. 6. Accumulation and subcellular distribution of Cucumber mosaic virus (CMV) $2 \mathrm{~b}$ protein mutants tagged with green fluorescent protein (GFP) at their N-termini. A, Western blot analysis of the accumulation of GFP-tagged wild-type and mutant $2 \mathrm{~b}$ proteins in infiltrated tissue (upper panel). B, Western blot analysis of accumulation of GFP-tagged wild-type and mutant $2 b$ proteins in infiltrated tissue in the presence of the tombusviral suppressor of gene-silencing P19 (upper panel). The lower panels of A and B are loading controls. C, Fluorescence in nuclei of epidermal cells derived from the four GFP-tagged $2 \mathrm{~b}$ proteins with deletions ( $\mathrm{b} \Delta \mathrm{NLS} 1,2 \mathrm{~b} \Delta \mathrm{NLS} 2,2 \mathrm{~b} \Delta \mathrm{NLS} 1+2$, $2 \mathrm{~b} \triangle \mathrm{KSPSE}$,) is shown in the left panels. Fluorescence derived from coinfiltrated fibrillarin-monomeric red fluorescent protein (Fib-mRFP), a nucleolar protein, is shown in the center panels. Right panels show both images merged. Bar represents $10 \mu \mathrm{m}$. 

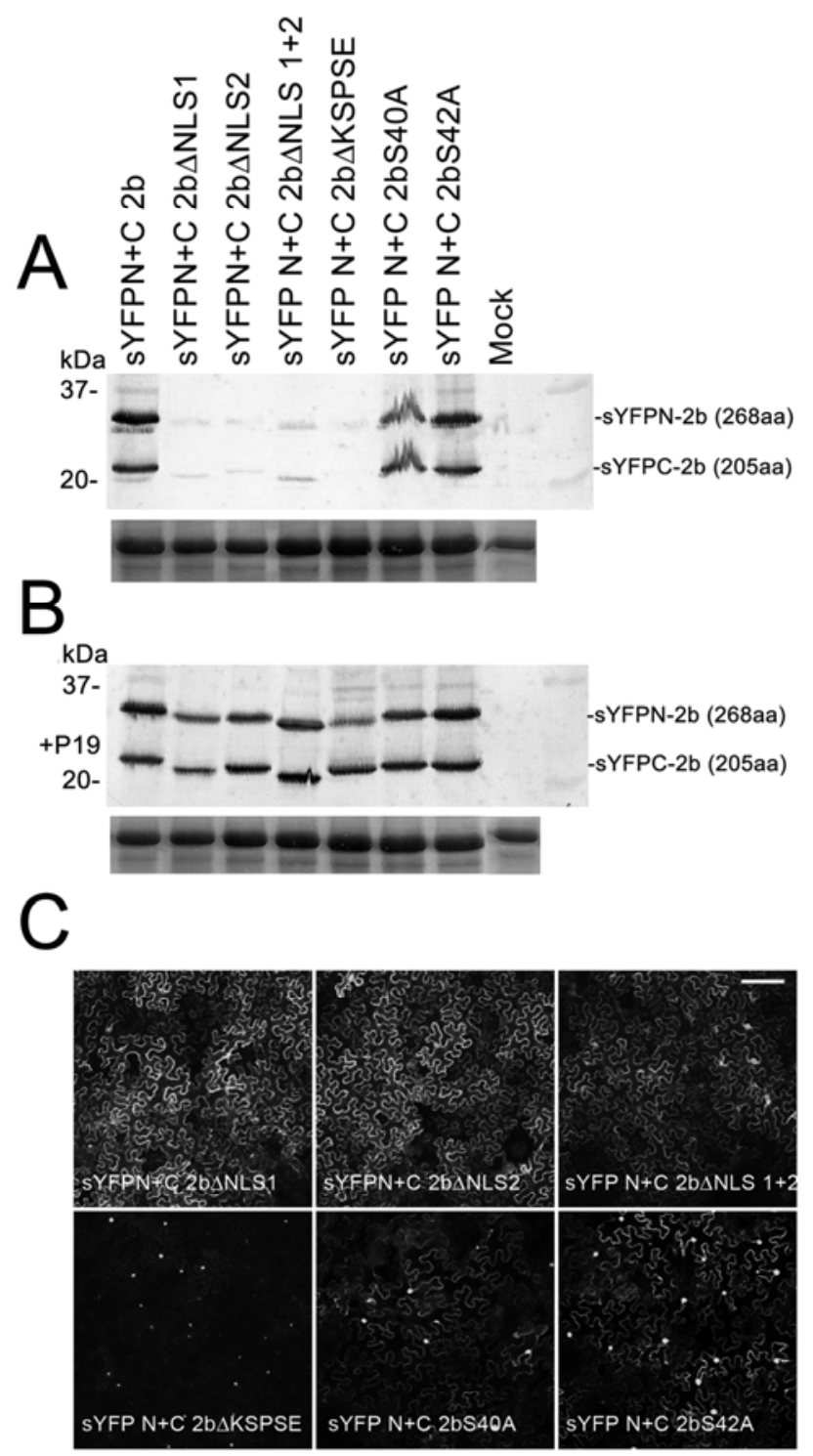

D

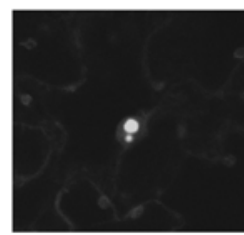

SYFPN $+\mathrm{C} 2 \mathrm{~b} \triangle \mathrm{KSPSE}$

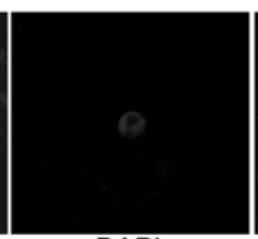

DAPI

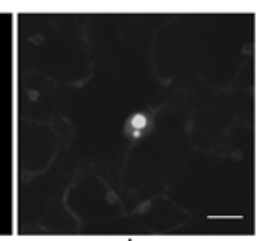

overlay
Fig. 7. Cucumber mosaic virus (CMV) $2 b$ protein mutants retain their ability to self-interact. CMV $2 \mathrm{~b}$ mutant proteins tagged at their N-termini with yellow fluorescent protein halves (sYFPN or sYFPC) were coexpressed transiently in Nicotiana benthamiana leaves by agroinfiltration. A, Western blot analysis of accumulation of sYFP-tagged wild-type and mutant $2 \mathrm{~b}$ proteins in infiltrated tissue (upper panel). B, Western blot analysis of the accumulation of sYFP-tagged wild-type and mutant $2 \mathrm{~b}$ proteins in infiltrated tissue in the presence of the suppressor of gene-silencing P19 (upper panel). The lower panels of A and B are loading controls. C, Fluorescence in fields of epidermal cells derived from the sYFP-tagged $2 \mathrm{~b}$ protein mutants. Fluorescence was predominantly cytoplasmic in the case of $2 \mathrm{~b} \Delta \mathrm{NLS} 1,2 \mathrm{~b} \Delta \mathrm{NLS} 2$, and $2 \mathrm{~b} \Delta \mathrm{NLS} 1+2$, whereas it was mainly nuclear and nucleolar for $2 \mathrm{~b} \Delta \mathrm{KSPSE}$. 2bS40A and 2bS42A were both nuclear and cytoplasmic, as was wild-type $2 \mathrm{~b}$. Bar in the upper right corner represents $100 \mu \mathrm{m}$. D, The mainly nuclear and nucleolar pattern of fluorescence derived from $\mathrm{s} Y \mathrm{FPN}+\mathrm{C} 2 \mathrm{~b} \Delta \mathrm{KSPSE}$ (left panel) was confirmed by 4'-6-diamino-phenylindol staining (middle panel) of individual nuclei. The right panel shows an overlay of the previous two images. Bar in the lower right corner represents $10 \mu \mathrm{m}$. fluorescence from interacting sYFP-tagged mutant $2 \mathrm{~b}$ proteins was similar to that displayed by the corresponding GFP-2b fusions.

BiFC showed that the four $2 \mathrm{~b}$ deletion mutants without local suppressor activity retained their ability to bind to AGO1 and AGO4, and their pattern of fluorescence was similar to that shown for the native sYFP-2b in Figure 4. The interaction of the four $2 b$ deletion mutants with AGO1 was mainly cytoplasmic. The subcellular fluorescence phenotype of the $2 \mathrm{~b}$ mutants interacting with $\mathrm{AGO} 4$ was mainly nuclear but not nucleolar, despite three of the mutants lacking one or both NLS (Supplemental Fig. 2). The two alanine substitution mutants displayed the same interaction phenotypes with AGO proteins as the native and the four $2 \mathrm{~b}$ deletion mutants (data not shown).

We tested whether the four mutants with no suppression of RNA silencing activity could complement each other in trans and restore suppressor activity. We coinfiltrated the four sYFPtagged mutants in all possible combinations of pairs. In none of the 16 cases was any RNA silencing suppressor activity observed (Supplemental Fig. 3).

The ability of four different $2 \mathrm{~b}$ deletion mutants with no local silencing-suppression activity in patch assays to bind synthetic siRNAs in vitro is compromised.

For RNA-binding studies, histidine-tagged versions of $2 \mathrm{~b}$ and the six mutant $2 \mathrm{~b}$ proteins were expressed in Escherichia coli and purified. Their ability to bind to a synthetic $21-n t$ dssiRNA was tested in gel retardation assays (Rakitina et al. 2006). At a protein/siRNA molar ratio of $15: 1$, the $2 \mathrm{~b}$ protein as well as mutant proteins $2 \mathrm{bS} 40 \mathrm{~A}$ and $2 \mathrm{bS} 42 \mathrm{~A}$ completely prevented siRNAs from entering the gels. By contrast, mutant proteins $2 \mathrm{~b} \Delta \mathrm{NLS} 1$ and $2 \mathrm{~b} \Delta \mathrm{NLS} 1+2$ did not retard entry of the synthetic siRNA into the gels. This indicated that, unlike $2 \mathrm{~b}$ and $2 \mathrm{bS} 40 \mathrm{~A}$ and $2 \mathrm{bS} 42 \mathrm{~A}$, these mutants lack the ability to bind small dsRNAs. Mutants $2 \mathrm{~b} \Delta \mathrm{NLS} 2$ and $2 \mathrm{~b} \Delta \mathrm{KSPSE}$ inhibited but did not completely prevent entry of synthetic siRNA into the gel (Fig. 8, upper and middle panels).

\section{DISCUSSION}

Suppressors of RNA silencing often appear to interfere with RNA silencing at multiple levels (Díaz-Pendón and Ding 2008). Although RNA binding seems to be common among most viral suppressors of RNA silencing (Lakatos et al. 2006; Mérai et al. 2006), interactions with host proteins have recently been identified for some suppressors, and such interactions may provide additional mechanisms to block RNA silencing (Baumberger et al. 2007; Bortolamiol et al. 2007; Díaz-Pendón and Ding 2008; Zhang et al. 2006). The dynamics of these interactions inside the cell are not well known. In the case of CMV 2b protein, its RNA silencing suppressor activity has been variously attributed to its nuclear targeting, its interaction with and inhibition of AGO1, or its ability to bind small RNAs in vitro. Here, we have carried out direct in vivo studies on the intracellular distribution of $2 \mathrm{~b}$ protein of CMV and on the occurrence protein-protein interactions as well as in vitro studies on interactions between $2 \mathrm{~b}$ and small RNAs, to assess their relative importance on the protein ability to suppress silencing.

We have first shown that CMV $2 \mathrm{~b}$ proteins tagged with fluorescent markers retain local silencing-suppression activity in infiltrated patch assays. This has allowed us to study the subcellular localization and interactions of tagged native and mutant $2 \mathrm{~b}$ proteins and correlate them to their biological activities.

We found that tagged $2 \mathrm{~b}$ protein induced a pattern of fluorescence that was mainly nuclear and, within nuclei, fluorescence was present in nucleoli and associated bodies, in which it did colocalize with fibrillarin (Fig. 1). Using BiFC, we 
showed that $2 \mathrm{~b}$ protein self-interacts in vivo. The BiFC-derived fluorescence phenotype was similar to that of GFP-2b, including the presence of $2 \mathrm{~b}$ in the nucleolus (Fig. 3). We suggest that homodimers could constitute the biological form of the $2 b$ suppressor, because GFP or sYFP fused to the $2 b$ protein N-terminus would hinder the oligomerization observed in vitro for TAV $2 \mathrm{~b}$ through that terminus (Chen et al. 2008).

We have also observed interactions between CMV 2b protein and AGO1 by BiFC that were shown previously in vitro by Zhang and associates (2006), using transiently expressed proteins and pull-down assays. The subcellular distribution of the complex was both cytoplasmic and nuclear (Fig. 4A and B), which seems to coincide with the subcellular distribution of AGO1 (Vaucheret 2007). In addition, we showed that the $2 b$ protein interacts with AGO4. The subcellular localization of the 2b-AGO4 complex was mainly nuclear but seemed absent from the nucleolus (Fig. 4C and D). AGO4 is a nuclear protein found throughout the nucleoplasm when tagged with GFP (Xie et al. 2004). A more recent report found that Myc-tagged AGO4 displayed euchromatic localization throughout the nucleus but could also accumulate in a distinct body, adjacent to or within the nucleolus ( $\mathrm{Li}$ et al. 2006). AGO4 binds to 24-nt siRNAs produced by DCL3, preferentially with 5'adenosines (Mi et al. 2008). These siRNAs could be required for the stability of nuclear AGO4 (Li et al. 2006). They are also required in the DNA methylation processes that regulate heterochromatinization and transcription, and the Q-CMV 2b protein was shown to inhibit methylation of DNA (Guo and Ding 2002). Using Arabidopsis dcl mutants, it was found that the DCL3generated 24-nt siRNAs did not repress the systemic spread of a CMV without a $2 \mathrm{~b}$ suppressor, whereas the 21- or 22-nt siRNAs did (Díaz-Pendón et al. 2007). This argues against any role of AGO4 in antiviral responses mediated by silencing. However, it was recently shown that the strong $2 \mathrm{~b}$ suppressor from the severe strain SD-CMV downregulated transcription of AGO4, whereas the weak $2 b$ suppressor from the milder strain Q-CMV did not (Ye et al. 2009). On the other hand, AGO4 but not AGO1 has been related to the inhibition of viral translation in cases of resistance $(R)$ gene-mediated plant disease resistance, which affect viruses that are not actual carriers of the avirulence gene. This is the case for the $N$ gene from $N$. glutinosa, which confers resistance to Tobacco mosaic virus, in which activation of $\mathrm{N}$-mediated resistance triggered inhibition of translation of Potato virus $X$ RNAs. This translation inhibition was absent if the AGO4 gene was silenced by viralinduced gene silencing (Bhattacharjee et al. 2009). Therefore, some evidence links AGO4 with antiviral responses, both in gene silencing or $R$ gene-mediated resistance pathways.

We analyzed the effects of mutating putative NLS and phosphorylation sites in the $2 \mathrm{~b}$ protein on its subcellular localization, its ability to interact with itself and other proteins in vivo, its silencing suppressor activity in patch assays, and its ability to bind synthetic siRNAs in vitro. The effects of these mutations on virus-induced symptoms have been characterized in Nicotiana spp. and A. thaliana by Lewsey and associates (2009). In that study, it was found that although wild-type CMV causes severe stunting and leaf distortion, viruses expressing mutant $2 \mathrm{~b}$ proteins with deletions of either one or both NLS or mutations in the putative phosphorylation domain were asymptomatic in tobacco or A. thaliana. In $N$. benthamiana, only the NLS1 deletion mutant caused symptoms that were very mild, while the other three mutants were asymptomatic. By contrast, the two Ala-substitution mutants displayed strong symptoms in all three hosts, although slightly more attenuated than those caused by the wild-type virus (Lewsey et al. 2009). In the present study, we showed, using patch assays, that the four deletion mutant proteins had lost local silencing- suppressor activity. In contrast, the two single Ala-substitution mutant proteins possessed a degree of silencing-suppression activity similar to that of wild-type $2 b$ protein. Analysis of the levels of $2 b$ protein accumulating during these transient expression experiments showed that the $2 \mathrm{~b}$ deletion mutant proteins did not accumulate to levels as high as wild-type $2 b$ protein. However, the two Ala-substitution mutant proteins accumulated to levels that approached those of the wild-type protein (Figs. 5 vs. 6A). These protein levels are similar to what was found in plants infected with CMV variants expressing these mutant $2 \mathrm{~b}$ proteins (Lewsey et al. 2009). However, with regard to symptoms in virus-infected plants, the two Ala-substitution mutants caused milder symptoms than wild-type CMV. Therefore, although the sequences mutated in the two Ala-substitution point mutants do not affect local suppression of RNA silencing, they must affect other aspects of the plant-virus interaction, in particular the induction of symptoms.

Lewsey and colleagues (2009) suggested two explanations for the low abundance of the $2 \mathrm{~b}$ protein variants encoded by the four deletion mutants. Either the low virus titer was responsible, or these proteins were less stable than the wild-type $2 \mathrm{~b}$ protein. An additional possibility is that, because these proteins cannot inhibit RNA silencing, the RNAs that encode these proteins (viral RNA [Lewsey et al. 2009] and ectopic mRNA [present study]) themselves became targets of silencing. The results of the present study show that this was indeed the case, since the presence of an additional silencing suppres-

$21 \mathrm{nt}$ SiRNAs

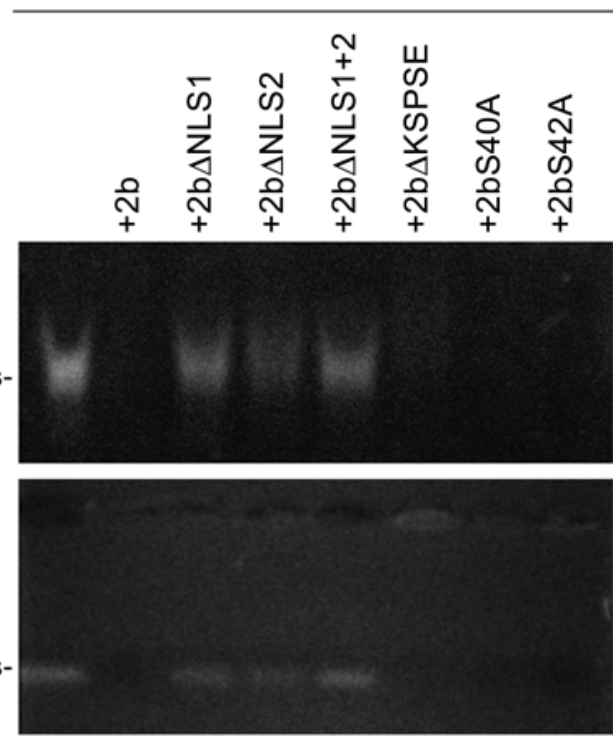

Dialyzed 2b proteins-

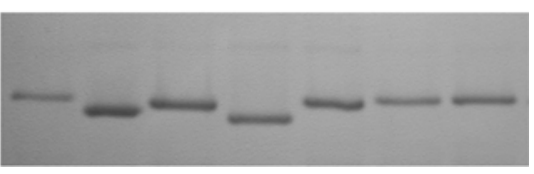

Fig. 8. Ability of native and mutant Cucumber mosaic virus (CMV) 2b proteins to bind to 21-nt small interfering RNAs (siRNAs) in vitro. Renatured proteins expressed in and purified from Escherichia coli and 5 pmol of synthetic siRNAs were incubated at a molar ratio of 15:1. Samples were subjected to $10 \%$ polyacrylamide gel electrophoresis (PAGE) (upper panel) or $2 \%$ agarose gel electrophoresis (middle panel). The first lane on the left shows how a 5 pmol siRNA sample incubated without protein runs in the gels. Incubation with native $2 \mathrm{~b}$ or with mutant proteins $2 \mathrm{bS} 40 \mathrm{~A}$ or $2 \mathrm{bS} 42 \mathrm{~A}$ completely prevented the siRNAs from entering the gels. By contrast, mutant proteins $2 \mathrm{~b} \Delta \mathrm{NLS} 1$ and $2 \mathrm{~b} \Delta \mathrm{NLS} 1+2$ were not able to prevent siRNAs from entering the gel, indicating that they failed to bind to them in vitro. Mutants $2 \mathrm{~b} \triangle \mathrm{NLS} 2$ and $2 \mathrm{~b} \triangle \mathrm{KSPSE}$ prevented siRNAs from entering the gel to some extent. A $12 \%$ PAGE gel of the protein samples used in the experiment is shown as proof to the use of similar protein levels (lower panel). 
sor (the TBSV P19 protein) restored their accumulation to levels similar to those seen for wild-type $2 \mathrm{~b}$ protein. The restorative effect of P19 on the accumulation of silencing-defective mutant $2 b$ proteins made possible our detailed study of the effects of the six mutations on protein subcellular localization and protein-protein interactions. Mutants lacking one or both NLS lost nuclear accumulation. By contrast, the mutant with the putative phosphorylation site deleted was mainly localized to nucleoli, suggesting it had lost its ability to remain in or return to the cytoplasm. Regarding the protein-protein interactions of the $2 \mathrm{~b}$ protein, the four deletion mutants without local RNA silencing suppressor activity retained their ability to selfinteract and to interact with AGO1 and AGO4. In combination with the data from the localization studies, these results show that neither its ability to bind AGO proteins or to localize to nuclei or nucleoli are sufficient for $2 b$ silencing suppressor activity. By contrast, when we tested the ability of the $2 \mathrm{~b}$ protein and its different mutant variants expressed to bind synthetic ds-siRNAs in vitro, we found that siRNA binding was either abolished or compromised in those mutants lacking silencing suppressor activity. Taken together, our results indicate that, of all the biological properties of the $2 \mathrm{~b}$ protein, small RNA binding may be most relevant in determining the functionality of the protein as a suppressor of local RNA silencing.

\section{MATERIALS AND METHODS}

\section{Vector DNA constructs.}

For transient expression in plants, proteins were cloned into the $35 \mathrm{~S}$ promoter-polylinker-NosTerminator T-DNA cassette of pROK2-based binary vectors. Wild-type Fny-CMV 2b protein was cloned previously into pROK2 (construct pROK-2b; Canto et al. 2002). The $2 \mathrm{~b}$ protein was cloned into pROK2 harboring either mRFP (pROK-mRFP) or GFP (pROK-GFP) after its amplification by polymerase chain reaction (PCR) with appropriate flanking restriction enzymes, to generate pROK constructs $2 b-m R F P$ and GFP-2b. The $2 b$ protein was also cloned into pROK2 harboring the HA peptide, to generate pROK construct $2 \mathrm{~b}-\mathrm{HA}$.

To generate pROK2-based vectors for BiFC, the YFP N- and C-terminal halves (amino acids 1 to 154 and 155 to 238, respectively [Bracha-Drori et al. 2004]) were amplified by PCR and were cloned into XbaI- and BamHI-linearized pROK2 vector. This insertion left a BamHI-SmaI-KpnI-SacI polylinker downstream of the inserted sYFP sequences in the pROKsYFPN and pROK-sYFPC BiFC constructs. The $2 \mathrm{~b}$ protein was then cloned into these constructs to generate pROK constructs sYFPN-2b and sYFPC-2b, respectively. In a similar way as the wild-type $2 b$, the six $2 b$ mutants (2b $\Delta$ NLS1, $2 \mathrm{~b} \Delta \mathrm{NLS} 2,2 \mathrm{~b} \Delta \mathrm{NLS} 1+2,2 \mathrm{~b} \Delta \mathrm{KSPSE}, 2 \mathrm{bS} 40 \mathrm{~A}$, and $2 \mathrm{bS} 42 \mathrm{~A}$ ) were amplified by PCR from plasmids harboring full-length cDNAs for mutant CMV RNAs 2 (Lewsey et al. 2009) and were cloned into the above-mentioned pROK constructs to generate the 24 constructs expressing GFP-, sYFPN-, or $s$ YFPC-tagged $2 b$ mutants. For the expression of $2 b$ protein in E. coli, both native $2 \mathrm{~b}$ as well as the six 2 b mutants with $\mathrm{C}$-terminal HA tags were transferred to BamHI- and SacI-linearized pQE30 expression plasmids (Qiagen, Hilden, Germany).

All GFP-tagged constructs harbored a red-shifted variant (Tu65; Clontech, CA, U.S.A.), which was not visible under the UV lamp. For UV lamp detection of fluorescence from a GFP reporter gene in the agroinfiltration patch assays, a binary vector expressing free eGFP was provided by J. Cubero (unpublished).

A pROK2 construct expressing fibrillarin fused to mRFP (Kim et al. 2007) was provided by M. Taliansky and S-H Kim (unpublished).
The coding sequences of $A G O 1$ and $A G O 4$ were amplified by reverse transcription PCR from $A$. thaliana mRNA, with appropriate flanking restriction sites, and were authenticated by DNA sequencing. The three PCR fragments were cloned into pROK-s YFPN and pROK-sYFPC, to generate the six constructs used in BiFC experiments.

\section{Transient expression of genes in plant tissues.}

Cultures of Agrobacterium tumefaciens C58C1 containing binary vectors were grown to exponential phase in Luria Bertani medium with antibiotics at $28^{\circ} \mathrm{C}$. For infiltration, each bacterial culture harboring a different T-DNA was diluted to a final OD at $600 \mathrm{~nm}\left(\mathrm{OD}_{600}\right)$ of 0.2. Different cultures harboring different TDNAs were then combined, and infiltration of the mixtures was performed on fully expanded leaves of $N$. benthamiana plants, using a syringe. For BiFC studies, Agrobacterium cultures carrying binary vectors with the corresponding SYFPN- and sYFPCfusions to the proteins of interest were coinfiltrated together into the same leaf tissue, each at $\mathrm{OD}_{600}$ of 0.2 .

\section{Imaging of fluorescence in cells and tissues.}

Epidermal cells in $N$. benthamiana-infiltrated tissue were monitored for fluorescence from either GFP, mRFP, or the reconstituted sYFP fluorophores of tagged proteins or from DAPI at 3 to $5 \mathrm{dpi}$. For DAPI staining, fresh leaf tissue was infiltrated with $2 \mu \mathrm{g}$ of DAPI per milliliter, prior to imaging. Imaging was conducted with Leica SP1 and SP2 (Leica Microsystems, Heidelberg, Germany) confocal laser scanning microscopes using fresh, nontreated leaf tissue and water immersion or water dipping objectives, as described previously (Canto et al. 2006).

\section{Local suppression \\ of silencing in agroinfiltrated patch assays.}

A free GFP reporter gene from a binary vector was expressed transiently in a $N$. benthamiana leaf, either coinfiltrated with the empty binary vector pROK2 (right side of leaf) or with another vector expressing a protein to be tested for silencing-suppression activity (left side of leaf). To monitor the effect of the second protein on the levels of fluorescence derived from the transiently expressed free GFP, leaves were illuminated at 3 to 5 dpi with a Blak Ray long wave UV lamp (UVP, Upland, CA, U.S.A.) and were photographed as described (Canto et al. 2002).

\section{Protein and nucleic acid analysis.}

For protein and nucleic acid analysis, $0.1 \mathrm{~g}$ of infiltrated tissue was ground to a powder with a pestle and liquid nitrogen. Total plant proteins were then extracted with $0.1 \mathrm{M}$ TrisHCl, pH 8, 10 mM EDTA, 0.1 M LiCl, 1\% 2-mercaptoethanol, and $1 \%$ sodium dodecyl sulphate and were boiled and fractionated in sodium dodecyl sulfate-polyacrylamide electrophoresis $15 \%$ gels. Gel proteins were wet-blotted onto nylon. For immunological detection of GFP, a rabbit GFP polyclonal antiserum, donated by G. Cowan (Scottish Crop Research Institute, Dundee, U.K.), was used. For detection of sYFPN-tagged proteins, a rabbit polyclonal antiserum against the $\mathrm{N}$ terminus of GFP was used (Sigma-Aldrich, St. Louis). For detection of the FnyCMV 2b protein, a mouse polyclonal antiserum was raised against both the $\mathrm{N}$ and $\mathrm{C}$ domains of the protein (amino acids 2 to 58 and 51 to 107 , respectively) overexpressed in E. coli. Blotted proteins were detected using commercial alkaline phosphatase-conjugated secondary antibodies and SigmaFast BICP/NBT substrate tablets (Sigma-Aldrich).

For mRNA and siRNA analysis, total nucleic acids were isolated from extracts, were fractionated in 1\% agarose and $15 \%$ acrylamide gels, respectively, and were blotted to nylon membranes as described (Canto et al. 2002). GFP mRNAs and 
siRNAs were detected using a GFP digoxigenin-labeled RNA probe, following the manufacturer's instructions (Roche Diagnostics GmbH, Mannheim, Germany).

\section{Gel-shift RNA-binding assays.}

Native and mutant $2 \mathrm{~b}$ proteins were expressed from plasmid pQE30 in E. coli and were purified by Ni-NTA chromatography (Qiagen) using their N-terminal 6xHis tags, followed by renaturation by dialysis, as described by Rakitina and associates (2006). For gel-shift RNA binding assays, two 21-nt small RNAs (5'-UGAUUGAGCCGCGCCAAUAUC-3' and 5'-UAU UGGCGCGGCUCAAUCAGA-3') were synthesized. Synthetic ds-siRNAs were formed by mixing equimolar amounts of these two small single-stranded RNAs, boiling them, and cooling them slowly to room temperature. For in vitro protein-RNA binding assays, 5 pmol of synthetic siRNAs were incubated with a $15 \times$ molar ratio of dialyzed protein in $10 \mathrm{mM}$ Tris- $\mathrm{HCl}$, $\mathrm{pH} 7.5,1 \mathrm{mM} \mathrm{MgCl} 2,1 \mathrm{~mm}$ dithiothreitol, and $50 \mathrm{mM} \mathrm{NaCl}$. Protein-RNA complexes were analyzed in either $10 \%$ acrylamide or $2 \%$ agarose Tris-acetate gels as described previously (Rakitina et al. 2006). RNA bands were detected by staining with SYBR Gold dye for acrylamide gels (Invitrogen, Carlsbad, CA, U.S.A.) or with ethidium bromide for agarose gels.

\section{ACKNOWLEDGMENTS}

We thank M. T. Seisdedos and F. González (Centro de Investigaciones Biológicas, the Spanish National Council for Scientific Research [CSIC]) for assistance on confocal microscopy and M. T. Serra-Yoldi for her help on the synthesis of $2 \mathrm{~b}$ antibody. We also thank M. Taliansky and S.-H. Kim for providing the binary construct expressing fibrillarin-mRFP. Work at T. C Canto's lab was funded by grants 2007401003 from the CSIC, grant AGL2008-03482 from the Spanish Ministry of Innovation and Science, and bilateral grant P2008RU03 from the Spanish Ministry of Innovation and Science and the Russian Foundation for Basic Research. I. González is recipient of a Ph.D. grant from the Spanish Ministry of Innovation and Science. L. Martínez, C. Llave, and F. Atencio were funded by the Spanish Ministry of Innovation and Science. P. Palukaitis was funded by the Scottish Executive Research Evaluation and Rural Affairs Directorate. M. G. Lewsey and J. P. Carr were funded by Biotechnology and Biological Sciences Research Council grant BB/D008204/1.

\section{LITERATURE CITED}

Bhattacharjee, S., Zamora, A., Tehseen, M., Sacco, M. A., Lambert, L. H., and Moffet, P. 2009. Virus resistance induced by NB-LRR proteins involves Argonaute 4-dependent translational control. Plant J. 58, 940-951.

Baumberger, N., Tsai, C.-H., Lie, M., Havecker, E., Baulcombe, DC 2007. The polerovirus silencing suppressor P0 targets ARGONAUTE proteins for degradation. Curr. Biol. 17:1609-1614.

Bortolamiol, D., Pazhouhandeh, M., Marrocco, K., Genschik, P., and Ziegler-Graff, V 2007. The polerovirus F box protein P0 targets ARGONAUTE1 to suppress RNA silencing. Curr. Biol. 17:1615-1621.

Bracha-Drori, K., Shichrur, K., Katz, A., Oliva, M., Angelovici, R., Yalovsky, S., and Ohad, N. 2004. Detection of protein-protein interactions in plants using bimolecular fluorescence complementation. Plant J. 40:419-427.

Brigneti, G., Voinnet, O., Li, W. X., Ding, S. W., and Baulcombe, D. C. 1998. Viral pathogenicity determinants are suppressors of transgene silencing in Nicotiana benthamiana. EMBO (Eur. Mol. Biol. Organ.) J. 17:6739-6746.

Canto, T., Cillo, F., and Palukaitis, P. 2002. Generation of siRNAs by TDNA sequences does not require active transcription or homology to sequences in the plant. Mol. Plant-Microbe Interact. 15:1137-1146.

Canto, T., Uhrig, J. F., Swanson, M., Wright, K., and MacFarlane, S. 2006. Translocation of Tomato bushy stunt virus P19 protein into the nucleus by ALY proteins compromises its silencing suppressor activity. J. Virol. 80:9064-9072.

Chapman, E. J., Prokhnevsky, A. I., Gopinath, K., Dolja, V. V., and Carrington, J. C. 2004. Viral RNA silencing suppressors inhibit the microRNA pathway at an intermediate step. Genes Dev. 18:1179-1186.

Chen, H. Y., Yang, J., Lin, C., and Yuan, Y. A. 2008. Structural basis for RNA-silencing suppression by Tomato aspermy virus protein $2 b$. EMBO (Eur. Mol. Biol. Organ.) Rep. 9:754-760.
Díaz-Pendón, J. A., Li, F. L., Li, W. X., and Ding, S. W. 2007. Suppression of antiviral silencing by Cucumber mosaic virus $2 \mathrm{~b}$ protein in Arabidopsis is associated with drastically reduced accumulation of three classes of viral small interfering RNAs. Plant Cell 19:2053-2063.

Díaz-Pendón, J. A., and Ding, S. W. 2008. Direct and indirect roles of viral suppressors of RNA silencing in pathogenesis. Ann. Rev. Phytopathol. 46:303-326.

Ding, S. W., Anderson, B. J., Haase, H. R., and Symons, R. H. 1994. New overlapping gene encoded by the Cucumber mosaic virus genome. Virology 198:593-601.

Ding, S. W., Shi, B. J., Li, W. X., and Symons, R. H. 1996. An interspecies hybrid RNA virus is significantly more virulent than either parental virus. Proc. Natl. Acad. Sci. U.S.A. 93:7470-7474.

Goto, K., Kobori, T., Kosaka, Y., Natsuaki, T., and Masuta, C. 2007. Characterisation of silencing suppressor $2 \mathrm{~b}$ of Cucumber mosaic virus based on examination of its small RNA-binding abilities. Plant Cell Physiol. 48:1050-1060.

Guo, H. S., and Ding, S. W. 2002. A viral protein inhibits the long range signaling activity of the gene silencing signal. EMBO (Eur. Mol. Biol. Organ.) J. 21:398-407.

Johansen, L. K., and Carrington, J. C. 2001. Silencing on the spot. Induction and suppression of RNA silencing in the Agrobacterium-mediated transient expression system. Plant Physiol. 126:930-938.

Kim, S., MacFarlane, S., Kalinina, N., Rakitina, D., Ryabov, E., Gillespie, T., Haupt, S., Brown, J., and Taliansky, M. 2007. Interaction of a plant virusencoded protein with the major nucleolar protein fibrillarin is required for systemic virus infection. Proc. Natl. Acad. Sci. U.S.A. 104:11115-11120.

Lakatos, L., Csorba, T., Pantaleo, V., Chapman, E. J., Carrington, J. C., Liu, Y. P., Dolja, V. V., Fernández-Calvino, L., López-Moya, J. J., and Burgyan, J. 2006. Small RNA binding is a common strategy to suppress RNA silencing by several viral suppressors. EMBO (Eur. Mol. Biol. Organ.) J. 25:2768-2780.

Lewsey, M., Robertson, F. C., Canto, T., Palukaitis, P., and Carr, J. P. 2007. Selective targeting of miRNA-regulated plant development by a viral counter-silencing protein. Plant J. 50:240-252.

M. Lewsey, M. Surette, F. C. Robertson, H. Ziebell, S. H. Choi, K. H. Ryu, T. Canto, P. Palukaitis, T. Payne, J. A. Walsh, and J. P. Carr. 2009. The role of Cucumber mosaic virus $2 \mathrm{~b}$ protein in viral movement and symptom induction. Mol. Plant-Microbe Interact. 22:642-654.

Li, C. F., Pontes, O., El-Shami, M., Henderson, I. R., Bernatavichute, Y. V. Chan, S. W., Lagrange, T., Pikaard, C. S., and Jacobsen, S. 2006. An ARGONAUTE4-containing nuclear processing center colocalized with Cajal Bodies in Arabidopsis thaliana. Cell 126:93-106.

Lucy, A. P., Guo, H. S., Li, W. X., Ding, S. W. 2000. Suppression of posttranscriptional gene silencing by a plant viral protein localized in the nucleus. EMBO (Eur. Mol. Biol. Organ.) J. 7:1672-1680.

Mayers, C. N., Palukaitis, P., and Carr, J. P. 2000. Subcellular distribution analysis of the cucumber mosaic virus 2 b protein. J. Gen. Virol. 81:219226.

Mérai, Z., Kerényi, Z., Kertész, S., Magna, M., Lakatos, L., and Silhavy, D. 2006. Double-stranded RNA binding may be a general plant RNA viral strategy to suppress RNA silencing. J. Virol. 80:5747-5756.

Mi, S., Cai, T., Hu, Y., Chen, Y., Hodges, E., Ni, F., Wu, L., Li, S., Zhou, H., Long, C., Chen, S., Hannon, G. J., and Qi, Y. 2008. Sorting of small RNAs into Arabidopsis Argonaute complexes is directed by the 5'terminal nucleotide. Cell 133:116-127.

Rakitina, D. V., Yelina, N. E., and Kalinina, N. O. 2006. Zinc ions stimulate the cooperative RNA binding of hordeiviral $\gamma \mathrm{b}$ protein. FEBS (Fed. Eur. Biochem. Soc.) Lett. 580:5077-5083.

Rashid, U. J., Hoffmann, J., Brutschy, B., Piehler, J., and Chen, J. C-H. 2008. Multiple targets for suppression of RNA interference by Tomato aspermy virus protein 2B. Biochemistry 47:12655-12657.

Vaucheret, H. 2008. Plant Argonautes. Trends in Plant Sci. 13:350-358.

Wang, Y., Tzfira, T., Gaba, V., Citovsky, V., Palukaitis, P., and Gal-On, A. 2004. Functional analysis of the Cucumber mosaic virus $2 \mathrm{~b}$ protein Pathogenicity and nuclear localization. J. Gen. Virol. 85:3135-3147.

Xie, Z., Johansen, I. K., Gustafson, A. M., Kasschau, K. D., Lellis, A. D., Zilberman, D., Jacobsen, S. E., and Carrington, J. C. 2004. Genetic and functional diversification of small RNA pathways in plants. PloS Biol. 2:e104. Published online.

Ye, K., Malinina, L., and Patel, D. J. 2003. Recognition of small interfering RNA by a viral suppressor of gene silencing. Nature 426:874-878.

Ye, J., Qu, J., Zhang, J. F., Geng, Y. F., and Fang, R. X. 2009. A critical domain of the Cucumber mosaic virus $2 \mathrm{~b}$ protein for RNA silencing suppressor activity. FEBS (Fed. Eur. Biochem. Soc.) Lett. 583:101-106.

Zhang, X., Yuan, Y. R., Lin, S. S., Tuschl, T., Patel, D. J., and Chua N. H. 2006. Cucumber mosaic virus-encoded 2b suppressor inhibits Arabidopsis Argonaute1 cleavage activity to counter plant defense. Genes Dev. 20:3255-3268. 